\title{
Dinâmica de quase-partículas supersônicas em um polímero do tipo Poly(Phenylene Vinylene) (PPV)
}

Fábio L. de O. Paula ${ }^{1, *}(\mathrm{PG})$, Leonardo L. Castro ${ }^{1}(\mathrm{PG})$, Pedro H. de O. Neto ${ }^{1}(\mathrm{PG})$

${ }^{1}$ Instituto de Física, Universidade de Brasília - UnB, Brasília, Brasil

Palavras-chave: GAP, Pólaron, Polímero.

*fabioluis@fis.unb.br

\section{Introdução}

Investigamos a dinâmica de portadores de carga em polímeros do tipo Poly(Phenylene Vinylene) (PPV) sob influência de campos elétricos externos. Especificamente, focamos a força crítica de campo necessária para a transição de subsônico para supersônico. O regime foi determinado para pólarons em PPV. A colisão entre quase-partícula e impurezas, em regime supersônico, foi investigada. Para tanto, realizamos uma dinâmica molecular de Ehrenfest através de um modelo hamiltoniano de Su-Schrieffer-Heeger.

\section{Metodologia}

A metodologia aqui adotada é uma simulação dinâmica de Ehrenfest baseada em um modelo molecular. Uma aproximação de primeira ordem de uma abordagem tightbinding com relaxação foi usada em conjunto com um hamiltoniano do tipo SSH, modificado para incluir os efeitos das impurezas e de um campo elétrico externo. Nas simulações numéricas realizadas, os elétrons são levados em conta resolvendo a equação de Schrödinger dependente do tempo, enquanto a rede é descrita classicamente num modelo massa-mola.

\section{Resultados e discussão}

Os resultados fornecem informações úteis sobre o comportamento da condutividade de polímeros condutores medidos para diferentes campos elétricos. Para caracterizar a transição do subsônico para o supersônico, o polímero é sujeito a diferentes regimes de campo elétrico e a velocidade terminal do pólaron é calculada. Assim, fizemos um gráfico de velocidade em função do campo elétrico aplicado e identificamos o valor do campo necessário para a transição sônico-supersônico.

\section{Conclusões}

Estudamos a dinâmica dos portadores de carga no regime supersônico em polímeros conjugados portadores de impurezas. Determinamos a força de campo crítica necessária para o transição do regime subsônico para supersônico em pólarons.

\section{Agradecimentos}

\section{Referência}

Este trabalho foi apoiado pelas agências brasileiras CNPq, CAPES e FAPDF.

L. A. Ribeiro, et al. The Journal of Chemical Physical 146, 144903 (2017) 